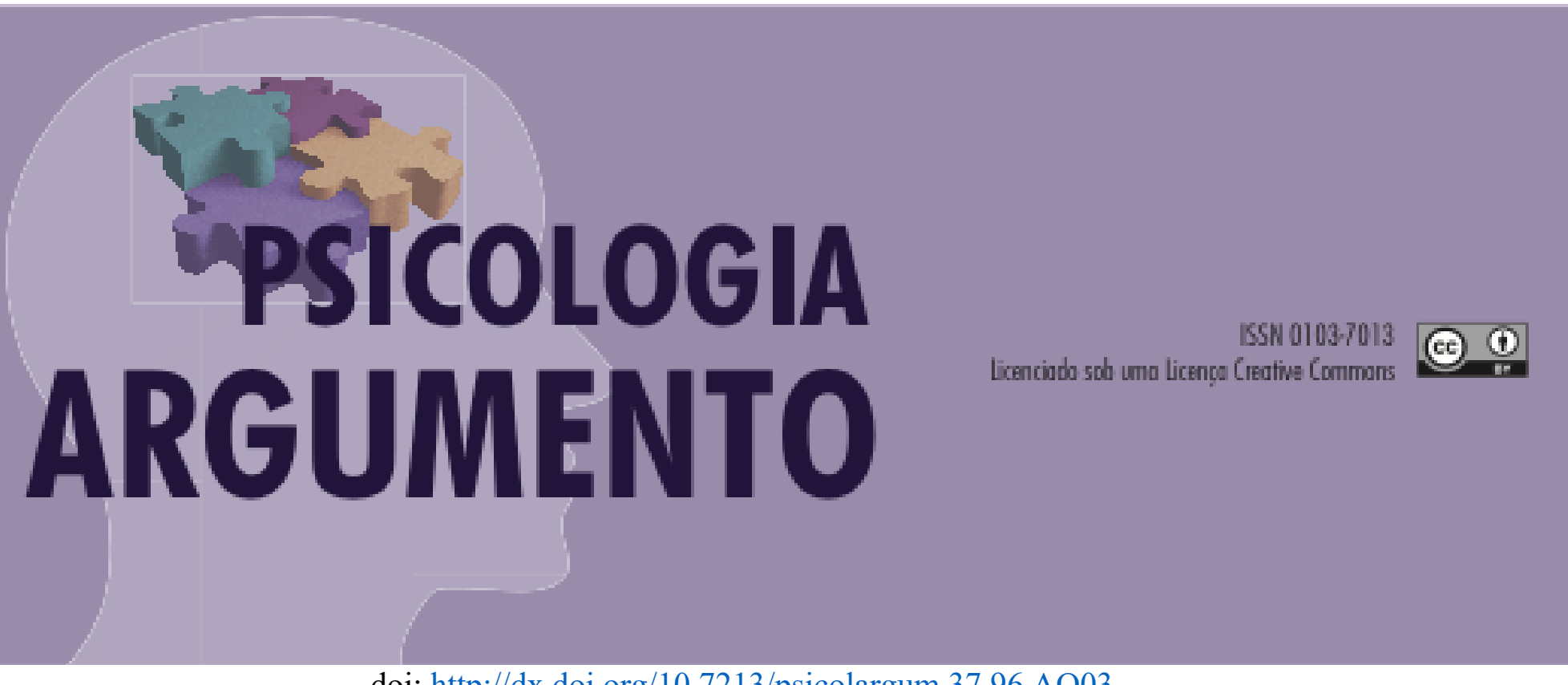

doi: http://dx.doi.org/10.7213/psicolargum.37.96.AO03

\title{
Resiliência de imigrantes haitianos frente ao processo de adaptação no novo país: impactos na saúde mental
}

Resilience of Haitian immigrants to the adaptation process in the new country: mental health impacts

Resiliencia de los inmigrantes haitianos al proceso de adaptación en el nuevo país: impactos en la salud mental

Jéssica Ortiz de Melo

https://orcid.org/0000-0002-3204-2403

CEFI - Centro de Estudos da Família e do Indivíduo. Email: melo-jessica@live.com

Patricia Fasolo Romani

https://orcid.org/0000-0003-4443-2748

InTCC - Ensino, Pesquisa e Atendimento Individual e Familiar. Email: pattyfaro@hotmail.com

\section{Resumo}

A imigração haitiana aumentou nos últimos anos devido a diversos fatores, sobretudo a partir do desastre ambiental ocorrido no país. O contexto da imigração envolve estressores que podem afetar de forma significativa a saúde física e mental do sujeito. O presente estudo teve como objetivo investigar os impactos da imigração na saúde mental de imigrantes haitianos que residem em Porto Alegre. Trata-se de um estudo qualitativo, de cunho exploratório. Os dados foram coletados através de uma entrevista semiestruturada e posteriormente interpretados por meio da análise de conteúdo temática, sendo discutidos com base nos referenciais teóricos da psicologia social e saúde coletiva. A partir dos dados obtidos foi possível compreender quais os 
comprometimentos do processo de imigração para a saúde mental dos imigrantes haitianos que participaram da pesquisa.

Palavras-chave: imigração; Haiti; resiliência; adaptação; saúde mental.

\begin{abstract}
Haitian immigration has increased in recent years due to several factors, especially from the environmental disaster that occurred in the country. The context of immigration involves stressors that can significantly affect the physical and mental health of the subject. This study aimed to investigate the impacts of immigration on the mental health of Haitian immigrants living in Porto Alegre. This is a qualitative, exploratory study. Data were collected through a semi-structured interview and later interpreted through thematic content analysis, being discussed based on the theoretical frameworks of social psychology and collective health. From the data obtained it was possible to understand what are the immigration process compromises to the mental health of the Haitian immigrants who participated in the research.
\end{abstract}

Keywords: immigration; Haiti; resilience; adaptation; mental health

\title{
Resumen
}

La inmigración haitiana ha aumentado en los últimos años debido a varios factores, especialmente por el desastre ambiental que ocurrió en el país. El contexto de la inmigración involucra factores estresantes que pueden afectar significativamente la salud fisica y mental del sujeto. Este estudio tuvo como objetivo investigar los impactos de la inmigración en la salud mental de los inmigrantes haitianos que viven en Porto Alegre. Este es un estudio cualitativo, exploratorio. Los datos fueron recolectados a través de una entrevista semiestructurada y luego interpretados a través de análisis de contenido temático, discutidos en base a los marcos teóricos de la psicología social y la salud colectiva. A partir de los datos obtenidos, fue posible comprender cuáles son los compromisos del proceso de inmigración para la salud mental de los inmigrantes haitianos que participaron en la investigación.

Palabras clave: inmigración; Haití resistencia adaptación; salud mental.

\section{Introdução}

A população haitiana passou por diversos problemas políticos que envolveram governos ditatoriais e uma profunda crise econômica e social. Entretanto no dia 12 de janeiro de 2010, o Haiti ficou estigmatizado após sofrer um terremoto que deixou um rastro de devastação, onde pessoas foram afetadas de alguma forma pelo evento, estimando-se que cerca de 222.570 homens, mulheres e crianças morreram. Após o desastre ambiental, muitos haitianos passaram a procurar países para imigrar, com o propósito de encontrar um local que lhes oferecesse trabalho, melhores condições de vida e, possivelmente, que pudessem residir com segurança.

O Brasil tem sido uma opção para essa população desde aquele desastre. No entanto, ao se deparar com a chegada de mais 2.000 haitianos, o governo percebeu que o cenário era inadequado para receber estrangeiros nessas condições (Godoy, 2011). Nessa perspectiva, é importante esclarecer que o termo "Imigrante" se refere à pessoa que 
escolhe se deslocar de seu local de origem para outro país, em busca de melhores condições de saúde, trabalho ou educação. Enquanto o termo "refugiado" é empregado, no contexto geral, para categorizar as pessoas que sobreviveram a conflitos ou perseguições, ou seja, necessitando de abrigo devido às ameaças impostas pelo seu país de origem (Alto Comissariado das Nações Unidas para os Refugiados [ACNUR], 2015). Segundo Jardim (2016), uma prática essencial para os procedimentos administrativos é o processo de identificar, selecionar e categorizar os imigrantes, uma vez que determina a elegibilidade e admissão de imigrantes e sua distinção de refugiados em novos contextos, de forma tanto individual como no coletivo. Corroborando o autor acima, a cultura de emigração é um aspecto relevante a ser analisado, considerando que mesmo frente às dificuldades do processo, há a sustentação do seu desejo de mudança (Brandes, 2014). Entende-se que o imigrante traz consigo diversas motivações para o deslocamento, no entanto, é importante ressaltar que o processo de mudança incide a partir de um contexto social, político e histórico, sendo influenciado pelas representações coletivas que atravessam a vida de cada pessoa, ou seja, sua cultura, valores, percepções e aspectos subjetivos (Dantas, 2016).

Em relação à imigração, alguns estudos relacionam este processo com um impacto negativo na saúde mental dos imigrantes, apontando implicações em diversos fatores de estresse presentes ao longo deste processo (Achotegui, 2008; Brandes, 2014; Carta et al., 2005; Franken; Coutinho \& Ramos, 2012; Ramos, 2009; Semedo, 2016). A qualidade de vida do ser humano depende de vários quesitos, entre os quais estão a autorregulação emocional, a motivação para concretizar os seus projetos pessoais e a capacidade de resiliência frente às adversidades, sejam estas físicas, sociais/culturais e/ou econômicas. Neste sentido, percebe-se que a dificuldade estabelecida pelo espaço em que o imigrante está inserido poderá influenciar no seu processo de adaptação, uma vez que as barreiras encontradas pelo caminho não serão somente fronteiras geográficas, mas socioeconômicas, culturais, interpessoais e subjetivas (Semedo, 2016). A resiliência é o conceito que exemplifica a flexibilidade de uma pessoa em se adaptar às demandas, mobilizando-se a partir de seus próprios recursos para enfrentar situações adversas, com intuito de manter o equilíbrio do corpo e da mente. Acredita-se que quanto maior a capacidade de resiliência de um imigrante, maior sua habilidade em manejar os problemas impostos pela sua condição social no novo país, e até mesmo no processo de aculturação (Brandes, 2014; Freitas \& Mendes, 2013; Ramos, 2009). 
O processo imigratório carrega diversos reveses que comprometem a saúde física e psíquica do imigrante. A experiência da migração envolve rupturas, que somadas a aculturação, causam intenso sofrimento psíquico, sendo semelhante ao sentimento de luto e de perda de identidade (Ramos, 2009; Franken, Coutinho \& Ramos, 2012; Trad, 2003; Semedo, 2016). Por outro lado, a imigração não é causa de um transtorno mental, e sim, fator de risco para o seu desenvolvimento. O surgimento de um transtorno mental em decorrência da experiência migratória depende de dois elementos: a vulnerabilidade do emigrante frente ao processo de imigração e a maneira como ele enfrenta as situações adversas. Porém, não se pode proferir que todos adoecem, embora a maioria vivencie níveis de estresse mais ou menos intensos, dificultando sua adaptação ao país de destino (Brandes, 2014).

Dentre as vivências negativas mais frequentes, sobretudo pelas mulheres imigrantes, destaca-se a violência física, exploração sexual, constrangimento e discriminação. Segundo Fernandes e Castro (2014), o preconceito $^{1}$ racial e xenofóbico são fatores que obstaculizam a adaptação dos imigrantes haitianos no Brasil, e são capazes de provocar a Síndrome do Imigrante, um quadro de estresse crônico e múltiplo, também chamada de Síndrome de Ulisses (terminologia utilizada para referenciar o herói grego que retorna à Tróia, após muitos anos suportando obstáculos e ameaças longe de seus entes queridos) (Achotegui, 2008; Brandes, 2014; Lima, 2016; Semedo, 2016). No novo território, o imigrante tem que conviver com diferenças na cultura, no idioma, nas percepções, além do fato de residir em condições de vida inadequadas, enfrentando seus medos, ansiedades, a solidão, o estranhamento e a invisibilidade (Achotegui, 2008).

De acordo com a descrição clínica, a síndrome apresenta características atípicas de uma sintomatologia depressiva, sintomas de ansiedade, somatização e dissociação (Carta et al., 2005). O quadro desenvolve-se de forma progressiva à medida que o imigrante se depara com as limitações do novo país, aumentando a sua vulnerabilidade. Entre os fatores de risco para o adoecimento estão a ausência de estrutura familiar, restritas opções de emprego, a necessidade abrupta de lidar com diferentes tradições,

\footnotetext{
${ }^{1}$ Preconceito e discriminação direcionados a quem possui uma raça ou etnia diferente, geralmente se refere à segregação racial.
} 
culturas e valores, a fome e a falta de moradia, além do preconceito - racismo $^{2}$ e xenofobia ${ }^{3}$. (Carta et al., 2005; Dias \& Gonçalves, 2007; Semedo, 2016; Trad, 2003; Von Mühlen, Dewes \& Leite, 2010).

Disposta a conhecer a realidade desses indivíduos, esta pesquisa teve como objetivos investigar os impactos da imigração na saúde mental de imigrantes haitianos, e identificar os motivos que levam o sujeito a sustentar o seu desejo de sair do país de origem.

\section{Método}

Trata-se de uma pesquisa qualitativa de cunho exploratório. $\mathrm{O}$ instrumento utilizado para captar as informações desejadas foi a entrevista semiestruturada. Nesse estudo foi utilizada a técnica snowball sampling (bola de neve) para a eleição dos participantes da pesquisa. Através da rede de contatos das pesquisadoras, do acesso a locais públicos onde esses imigrantes costumam transitar, e de indicações que eles mesmos forneceram, chegou-se até aqueles que se encaixavam no perfil desejado; nessa ocasião, eles foram convidados para ingressar na pesquisa e para tanto, receberam informações quanto aos objetivos, riscos e benefícios, ausência de remuneração e possibilidade de encaminhamento para atendimento gratuito no serviço de psicologia da faculdade a qual a pesquisa estava vinculada, no caso de evidenciarem prejuízo e/ou sofrimento significativo.

Mediante o aceite, os sujeitos assinaram o Termo de Consentimento Livre e Esclarecido e ficaram com uma cópia. Foram entrevistados cinco imigrantes haitianos (2 mulheres e 3 homens), acima de 18 anos, que até aquele momento, estavam residindo há no máximo três anos na cidade de Porto Alegre. As entrevistas foram realizadas em locais de acordo com a escolha de cada participante, na rua (centro da cidade de Porto Alegre e do município Viamão) e no shopping (praça de alimentação).

\footnotetext{
${ }^{2}$ Comportamento hostil dirigido às pessoas ou aos grupos sociais que pertencem a outras raças e/ou etnias.

${ }^{3}$ Receio, medo ou rejeição, direcionado a algo ou alguém que não faz parte do local onde se vive ou habita; hostilidade.
} 
As respostas passaram por uma análise de conteúdo temática (Bardin, 1977), cujas interpretações e ilustrações serão expostas a seguir. A análise temática é compreendida como um processo indutivo e dinâmico de atenção, que consiste no recorte do conteúdo, uma vez que possibilita visualizar as mensagens explícitas e implícitas no contexto (Campos, 2004). Para a discussão das informações levantadas utilizou-se os referenciais teóricos da psicologia social e da saúde coletiva. O projeto em questão foi compartilhado na Plataforma Brasil, para fins de análise de Comitê de Ética em Pesquisa, e colocado em prática somente após ser aprovado, respeitando as diretrizes e normas regulamentadoras de pesquisas envolvendo seres humanos, conforme a resolução 466/12 e 510/16 do Conselho Nacional de Saúde (CNS).

\section{Resultados e Discussão}

As categorias descritas e ilustradas a seguir foram estabelecidas a partir das respostas às entrevistas e dos referenciais teóricos escolhidos para discutir e analisar os dados.

Causas da imigração

Nesta categoria estão incluídas as questões relacionadas aos motivos que levaram os participantes desta pesquisa a migrar do seu país de origem, Haiti, e escolher o Brasil como destino. Percebe-se que aspectos relacionados a problemas políticos, sendo destacadas as falhas do governo frente ao desamparo a população haitiana, bem como a carência de emprego no país, foram as causas mais citadas. Uma participante que trabalha de forma autônoma fez o seguinte relato:

"Problemas políticos, governo que não ajuda, faltavam coisas para nós, porque eles (governo) não entregam, só guardam para eles mesmos. Por isso agora todos estamos em busca, luta, vida! [...] Emprego era o mais difícil de se encontrar lá no Haiti" (Participante $\mathrm{n}^{\circ} 1-\mathrm{P} 1$ ).

Segundo Moraes, Andrade e Mattos (2013), a população haitiana encontra-se com o sistema político desorganizado, o que compromete a economia do país. Compreendese que a realidade socioeconômica e política presente nesse país ocasiona um quadro de completa desesperança, fazendo com que muitos haitianos optem por deixar seu país rumo ao Canadá, Estados Unidos, França, Antilhas Francesas, República Dominicana e 
Brasil. Considerando que o Haiti é a primeira república negra do mundo, é importante enfatizar que essa recente crise generalizada não pode ser abordada de forma pontual e simplória. É preciso conhecer a história do Haiti, que é estigmatizado por intervenções, regimes ditatoriais, corrupção e desastres ambientais, sendo visto como um dos países mais pobres da América, com um passado de sofrimento, apontado pela desigualdade social, violência e instabilidade política desde o início de sua formação (Moraes, Andrade \& Mattos, 2013).

Observa-se que a ausência de emprego no Haiti é um problema enfatizado pela ansiedade dos participantes durante as entrevistas, demonstrando a urgência em encontrar trabalho e manter um salário para auxiliar os familiares que permanecem no país. Um dos participantes expressou:

"Primeira coisa de sair de lá e vir para cá é porque lá não tem mais serviço. E quando preciso de dinheiro para ganhar é mais difícil, ganhar dinheiro para minha família, porque é muito sofrimento lá [...] Então eu vim aqui (Brasil) porque tem mais serviço" (P5).

Nesse sentido, as dificuldades e obstáculos impostos aos haitianos em seu próprio país, fazem com que grande parte busque imigrar para o Brasil. Há muito tempo o Haiti encontra-se destroçado, com índices de desemprego na ordem de $80 \%$ e com mais de $70 \%$ da população tendo acesso a apenas uma refeição por dia (Pereira, 2007).Nos relatos foi evidente a preocupação dos entrevistados com os familiares, uma vez que o imigrante tem como responsabilidade prover aqueles que ficaram lá (Fernandes \& Castro, 2014).

"Eu mando dinheiro para eles todos os meses para ajudar a arrumar a casa para ela morar, ela tem casa lá, mas não é boa, a casa "quebrou" então eu mandei dinheiro para ela fazer outra" (P3).

Logo, entende-se que o maior objetivo dos imigrantes é enviar remessas para manutenção dos seus familiares que permaneceram no Haiti, além de conquistar melhores condições financeiras para si próprios. O processo de migração necessita de recursos, uma vez que as viagens de longa distância (como França e Brasil) demandam economias que envolvem, em muitos casos, todos os membros da família, pois o projeto migratório é 
uma estratégia familiar e não somente individual de subsistência (Mejía, Cazarotto \& Granada, 2014; Zeni \& Filippim, 2014).

\section{Dificuldades encontradas}

Nesta categoria serão abordadas as dificuldades que os participantes percebem desde a sua chegada ao Brasil, bem como o preconceito que sofrem no processo de adaptação ao novo país. Embora alguns haitianos consigam construir suas vidas além das fronteiras, ainda há barreiras culturais e sociais que dificultam o seu caminho. Com a chegada de haitianos ao Brasil, o país passa a sofrer uma crise migratória que surge a partir de uma sociedade despreparada em termos de legislação, da escassez de políticas de acolhimento e de emprego (Baeninger \& Peres, 2017). Observa-se que a carência de trabalho na chegada ainda emerge como uma das dificuldades mais encontradas:

"Eu fiquei muito tempo desde que eu cheguei aqui no Brasil sem serviço; depois fiquei grávida e aí que não consegui mais serviço [...] Acho que isso é o mais difícil, porque se a gente não trabalha, não consegue fazer nada. ”(P3)

Os sujeitos desta pesquisa disseram estar em processo de adaptação econômica e cultural, situação tida por eles como transitória, ainda que por vezes demonstrem temor pela continuidade do visto de permanência no país (Zeni \& Filippim, 2014).

"Tem que ficar tranquilo, porque eu venho de outro país, porque eu vim para o país dele (brasileiro) para trabalhar, então só posso ficar tranquilo" (P5).

No que se refere ao grau de escolaridade, de acordo com o registro no Ministério do Trabalho e Emprego (2011), grande parte dos imigrantes vindos do Haiti para cá são homens, com idade entre 20 e 30 anos e possuem escolaridade de ensino médio e/ou fundamental incompleto. Porém, há registros da vinda de advogados, engenheiros e enfermeiros, que, embora sejam profissionais com formação acadêmica de nível superior, estão à procura de oportunidades de trabalho mesmo em outros setores da economia, tais como na indústria e na construção civil (Zeni \& Filippim, 2014). 
"Parece que eles pensam que quando haitiano vem aqui (Brasil) que não sabe ler, não sabe nada, mas tem muito haitiano que vem que é advogado, tem doutor de dois, três anos de faculdade [...] eles querem que haitiano faça tudo como um escravo, mas não sou escrava, eu fiz escola como todo mundo [...] os haitianos que vem para cá não são desses mais pobres mesmo, são mais classe média, meia classe, você entende? Porque muitos haitianos não vão conseguir pagar o ticket, as passagens, aluguel, são muitas coisas para pagar" (P1).

Ainda que boa parte desses indivíduos possua qualificação profissional, como formação em curso técnico ou curso superior, além de falarem até quatro idiomas, entre eles o espanhol, o inglês e o francês, são recebidos neste solo, eles não têm suas aptidões aproveitadas. Para piorar o cenário, acabam sendo explorados, especialmente os que estão em condição ilegal no país, servindo como mão de obra barata (Moraes, Andrade \& Mattos, 2013).

Nos relatos acima, percebe-se que imigrantes haitianos sofrem diversos tipos de discriminação. Cogo (2019) afirma que eles costumam ser atraídos pela suposta democracia racial, contudo ela é um mito; a raça ${ }^{4}$ segue demarcando espaços e produzindo desigualdades até mesmo entre brasileiros. Apesar de o Haiti ser o primeiro país negro a declarar independência e conquistar a abolição da escravidão no mundo, ainda há uma visão estigmatizada de escravo (Mejía, Cazarotto \& Granada, 2014).

"Tem as pessoas, os brasileiros, que não gosta de estrangeiro, pessoas muito racistas também [...] No ônibus, a gente vê que a pessoa não quer sentar no mesmo banco, não gostam de estrangeiro, eles têm medo, entendeu”. (P2)

O racismo acontece a partir da diferenciação cultural, justamente pelo fato de ser estrangeiro e fazer parte de um grupo minoritário, que é percebido como detentor de uma cultura inferior à dos dominantes. $\mathrm{O}$ grupo dominante tende a utilizar esse subterfúgio

\footnotetext{
${ }^{4}$ Categorização que pretende classificar os seres humanos, pautando-se em caracteres
} físicos e hereditários. 
como justificativa para praticar a exclusão do grupo dominado, afirmando que estes são incapazes de seguirem as normas locais vigentes (Diehl, 2016).

Sobre as políticas de inclusão e aculturação, Barros (2016) presume que a criação da Resolução Normativa (RN) 97/2012, que dispõe sobre a concessão do visto permanente aos haitianos, foi uma manobra do governo brasileiro para acolher legalmente esse grupo. É comum os haitianos escolherem vir para cá, pautados na imagem que têm deste país: facilidade na entrada e permanência, empregos disponíveis ou possibilidades de formação profissional, destino provisório. A criação do visto humanitário para os haitianos e, posteriormente, para outros povos, é o passo mais simbólico para a construção de políticas migratórias brasileiras; as alterações na legislação almejam o reconhecimento dos direitos dessas pessoas. Não obstante, as atuações do governo não se direcionaram para a constituição de uma política com bases sólidas, mas sim para gerenciar situações de crise em resposta às pressões da sociedade civil (Fernandes \& Faria, 2017).

\section{Vínculos}

Nesta categoria questiona-se acerca das relações familiares e interpessoais dos entrevistados, ressaltando a forma como os imigrantes interagem com seus parentes e amigos do Haiti, bem como também os vínculos de amizade construídos neste país. Nas entrevistas, os participantes destacaram a praticidade e acessibilidade de aplicativos para manter contato com os parentes.

"Falo pelo whatssap e messenger, todos os dias" (P1).

"Quando to no trabalho não falo, espero chegar em casa, mas falo todos os dias". (P5)

"Whatssap e messenger (facebook). Não falo todos os dias, falo um dia na semana" (P4).

O aplicativo Whatsapp formou um público incomum, tornando-se um recurso acessível entre pessoas que, seja por condição de refúgio ou por imigração, deixaram suas habitações sem destino certo. Considerando que o aplicativo é gratuito, possui um histórico relativamente bom de manutenção da privacidade e da segurança do usuário. Neste sentido, as redes sociais de comunicação surgem como uma ferramenta tecnológico que auxilia o imigrante no processo de adaptação no novo país, visto que proporciona, de algum modo, sustentar os vínculos nas relações interpessoais (Editora Abril, 2017). 
No que diz respeito aos vínculos de amizade construídos neste país, grande parte dos entrevistados destacaram suas relações de amizade com senegaleses e outros haitianos, aspecto que pode estar associado a identificação pela condição de estrangeiro ou por ser da mesma pátria, e assim manter aspectos culturais da sua origem. É mister assinalar que cultura não é mais compreendida como um conjunto de crenças e práticas tradicionais, transmitidas de forma transgeracional, mas de modo dinâmico, ou seja, um sistema flexível, que compõe um referencial por meio do qual os indivíduos e os grupos sociais determinam as respectivas identidades e ajustam as suas vidas (Lechner, 2007).

“Com meus amigos haitianos [...] só com os haitianos mesmo [...] Jogo futebol [...] meus amigos brasileiros, são meus colegas de trabalho". (P2)

"Amigos? Sim, hatianos". (P4)

"Eu tenho dois amigos, um amigo e uma amiga brasileiros, porque ela fala francês, então ela fala comigo tudo em francês; o marido dela também fala". (P3)

A rede de apoio social é identificada pelas relações de um sujeito nas diversas situações da vida cotidiana, na família e na sociedade (Lavall, Olschowsky \& Kantorski, 2009). As redes de apoio são fundamentais para a promoção de saúde e bem-estar, bem como para o processo de adaptação do indivíduo frente aos acontecimentos da vida.

De acordo com La Rúa (2004), os modelos tradicionais referentes a adaptação do imigrante ao local de destino eram fundamentados na aculturação unidirecional, processo no qual o imigrante agrupa-se psicológica e socialmente à cultura do país de destino. Todavia, a partir do modelo de Berry (1989), citado pelo referido autor, a adaptação passa a ser percebida como um processo bidirecional, que abrange, respectivamente, uma redefinição da relação do imigrante com a cultura do local de acolhida e de sua cultura de origem.

O processo em si passa por fases, dependendo de como se desenvolver: a integração, caso o indivíduo desenvolva relações significativas com a sociedade de destino e de origem; a marginalização, quando não houver vínculo com nenhuma das duas, passando por relações assimétricas, como a separação, quando a relação é mais significativa com a sociedade do país de origem; e a assimilação, cuja relação é mais significativa com o país de acolhida (La Rúa, 2004). 


\section{Saúde física e mental}

Nesta categoria estão incluídos sintomas físicos e psíquicos que o imigrante pode apresentar frente ao processo de adaptação, o histórico de doença mental na família dos participantes, e se houve a necessidade de cuidados médicos desde que chegou ao país. O processo imigratório não representa, de forma exclusiva, um fator de risco, porém os estressores presentes em cada etapa acarretam um impacto significativo na saúde física e mental do sujeito. As repercussões variam de acordo com o tipo de imigração (legal/ilegal), a disponibilidade de serviços de saúde no local de acolhimento e o ambiente, assim como a cultura de origem da pessoa que se muda. Sendo assim, os efeitos negativos sobre a saúde do ser humano dependem de quem, quando e para onde ele imigra (Dias \& Gonçalves, 2007).

Segundo Achotegui (2008), a síndrome de Ulysses se estabelece a partir de alguns sintomas físicos e psíquicos, dentre estes a cefaleia é um dos sinais mais característicos, corroborando os dados da sua pesquisa anterior (Achotegui, Lahoz, Marxen\& Espeso, 2005), na qual 76,7\% dos pacientes com a síndrome apresentavam essa queixa. As dores de cabeça descritas pelos imigrantes são, geralmente, do tipo tensional e estão relacionadas às preocupações recorrentes. Dentre os sintomas físicos, esse tipo de dor foi citado por todos os entrevistados.

"Mais dor de cabeça, porque eu sempre fico pensando nos parentes de lá". (P2).

"Sinto mais dor de cabeça [...] Sinto por uns dois dias [...] quando penso na minha mãe”. (P4).

A queixa de dor de cabeça associa-se diretamente outro sintoma, que são as preocupações excessivas, presentes no discurso de todos. Esse sentimento de apreensão está relacionado a extrema complexidade e dificuldade que a mudança de país causa ao sujeito, que vivencia de forma acumulativa sentimentos conflitantes que demandam tempo para serem integrados. Esse processo exige a tomada de decisões importantes, por vezes em um curto período e com poucos meios de análise, implicando em uma tensão excessiva (Achotegui, 2008).

"Tenho muita dor de cabeça [...] Quando eu ficava nervosa, quando eu pensava às vezes na minha família, ficava nervosa e triste" (P3). 
Corroborando as informações acima, outro estudo (Mejía, Cazarotto \& Granada, 2014), revelou que os imigrantes que não conseguiram trazer seus parentes para o local de assentamento, têm manifestado um estado depressivo, considerando que o sistema familiar proporciona ao sujeito um sentido de proteção. Além disso, as dificuldades financeiras desencadeiam sinais de angústia e ansiedade intensa, uma vez que os imigrantes não tinham consciência da real situação socioeconômica do Brasil (Mejía, Cazarotto \& Granada, 2014). Para Achotegui (2008), os sinais recorrentes de preocupação propiciam o aparecimento de outros sintomas, que, experienciados em conjunto, podem causar danos à rotina do sujeito.

"Eu senti preocupação, medo, pouco de angústia. Não dá para sair do país com problema de política e vir para cá e ver armas, violência na rua”. (P1).

Também foi possível perceber durante as entrevistas, que apenas uma participante referiu ter realizado tratamento para depressão, quadro que iniciou após ter sofrido a perda do seu esposo, enquanto residiam no Brasil.

"Desde que perdi meu marido, que eu tive a depressão [...] Eu já senti sensação de estar perdida e pensei que Deus podia levar minha vida, porque eu não queria viver mais". (P3).

É essencial esclarecer que o quadro depressivo típico não se encaixa na síndrome do imigrante, mas tem uma conotação semelhante devido ao sentimento de tristeza constante, arrependimento intenso e/ou desolação. Já a apatia é substituída pelo empenho, uma vez que demostram motivação para fazer coisas, estando dispostos a lutar e trabalhar (Achotegui, 2008).

Quanto à necessidade de cuidados médicos no país de chegada, o processo imigratório pode afetar negativamente a saúde do sujeito, aumentando a sua vulnerabilidade frente aos empecilhos. Desta forma, são imprescindíveis normas e práticas institucionais que atendam às demandas específicas dessa população, de forma que garanta o direito à saúde, como para os nativos (Guerra \& Ventura, 2017). 
“Sim (busca por cuidados médicos), na UPA, duas vezes [...] me senti bem”. (P4).

"Eu me senti bem lá [...] Eu sempre vou para o hospital”. (P2).

Fernandes e Castro (2014) afirmam que muitos imigrantes são bem atendidos pelo Sistema Único de Saúde Brasileiro (SUS), quando precisam tanto de pronto atendimento emergencial, como medicina preventiva. Entretanto alguns se queixam do atendimento desse serviço de saúde, sobretudo pela demora, situação que não se diferencia da vivenciada pelos brasileiros que utilizam o mesmo recurso. Certos entrevistados confirmam essa informação:

"Vou para hospital se passo mal [...] No hospital conceição, já fui a UPA também, mas demora muito". (P1).

"Eu nunca vou no hospital da prefeitura [...] Então eu vou nos outros doutores (particulares) para ficar bem". (P3).

O idioma é um dos obstáculos listados tanto no estudo de Ferreira, Oliveira e Dutra (2018), como no de Alves et al (2019), associado também a expressão da sintomatologia apresentada, o que pode afetar a prestação de atendimento adequado.

\section{Atividades de Lazer}

Nesta categoria estão incluídos os questionamentos sobre como os participantes procuram se ocupar nas horas vagas. O intuito é compreender se eles procuram atividades que lhes proporcionem prazer e/ou socialização em outros ambientes, exceto no contexto de trabalho. As atividades de lazer auxiliam na redução do nível de estresse habitual (Elias \& Dunning, 1992), após o cumprimento das obrigações (Ferreira, 2010). O tempo pode ser dividido entre período de trabalho e período livre, os quais englobam desde atividades sociais, administração familiar até entretenimento. A tendência do sujeito enquanto trabalhador, sobretudo no caso desses estrangeiros, será destinar apenas uma parte do seu tempo livre para o lazer.

De acordo com Ferreira (2010), o tempo livre é construído com o objetivo de superar as dificuldades e trazer melhorias na qualidade de vida. Todavia nem tudo o que é feito no tempo livre é considerado lazer, ainda que almeje o desenvolvimento pessoal e social. 
"Em casa eu não faço nada, porque eu saio de casa as seis e chego em casa as sete na noite. Então quando chego em casa, eu cansei, então vou tomar um banho, janto, lavo a louça”. (P3)

"Eu trabalho durante o dia e quando chega em casa eu descanso, vou olhar televisão". (P5)

"Eu jogo futebol uma vez por mês [...] Eu gosto de sair no fim de semana para Canoas, Shopping Total, Iguatemi. Sempre saio com meus amigos [...]”. (P2)

Poucos são os haitianos que participam de atividades coletivas, tais como o futebol. O uso do tempo restante após a execução das tarefas laborais formais, usualmente envolve trabalhos domésticos ou um evento religioso, seja no âmbito familiar ou coletivo. Em geral, percebe-se que essa população tende a procurar eventos pré-estabelecidos ao invés de organizá-los por conta própria (Cotinguiba, 2014).

Elias e Dunning (1992) classificaram o uso do tempo fora do ambiente profissional em três categorias, conforme o grau de rotina:

a) rotinas do tempo livre (atividades rotineiras e consideradas pouco prazerosas): o tempo é designado ao atendimento das próprias necessidades biológicas, como o cuidado com o corpo e rotinas familiares;

b) atividades de lazer (aquelas consideradas não rotineiras, que geram a liberação controlada das emoções): atividades sociáveis como um jantar ou uma viagem, o lazer comunitário e o jogo;

c) atividades intermediárias ou de formação e autodesenvolvimento (menos rotineiras e gratificantes, mas que exigem disciplina): são reservadas ao desenvolvimento pessoal por meio da participação política, religiosa, filantrópica, entre outras.

A crença religiosa serve como fonte de apoio e socialização aos entrevistados. A religião propicia um sentido de propósito e significado na vida; ela está diretamente relacionada à resiliência e à resistência ao estresse patológico. A religiosidade é vista como fator de proteção contra doenças crônicas, no enfrentamento de situação de risco e vulnerabilidade social (Cabistany \& Rombaldi, 2014; Lawler \& Younger, 2002; Panzini \& Bandeira, 2007).

"Eu trabalho todo o domingo e sábado eu vou à igreja". (P3)

"Eu saio com eles (amigos) para igreja, a evangélica”. (P4) 


\section{Considerações Finais}

Migrar não é algo novo para os haitianos; faz parte do seu cotidiano há algum tempo, conforme Cotinguiba (2014). Após passar por diversas dificuldades socioeconômicas, políticas e ambientais, parte desse povo escolheu o Brasil como lugar para morar. Desde a chegada neste país, ela busca incansavelmente melhores condições de vida, sobretudo por trabalho, pois necessitam sustentar os familiares que ficaram no Haiti.

A entrada de haitianos possibilitou que o território brasileiro passasse a ser uma escolha de vida para outras nacionalidades, principalmente de refugiados (como, por exemplo, os senegaleses). Esse fato requer a alteração da legislação referente aos estrangeiros, principalmente os que fogem da guerra, da fome e da morte. Rodrigues (2013) avalia o processo de regularização do imigrante como burocrático e demorado. Fica cada vez mais evidente que o Brasil ainda possui aspectos problemáticos a serem decididos para evoluir nesse âmbito.

Os fatores sociopolíticos e ambientais podem se tornar barreiras que dificultam o processo de adaptação do imigrante no novo país. Além da saudade em relação à família e amigos que permanecem residindo no Haiti, nota-se que o preconceito racial e a xenofobia sofrida por vários nativos, impedem que eles se adaptem sem tanto sofrimento. As adversidades que compõem o processo de aculturação ocasionam agravos à saúde mental dos haitianos que estão residindo aqui, e ao atingirem um nível de desgaste múltiplo e crônico, transformam-se na Síndrome do Imigrante ou Síndrome de Ulisses, cujos sinais usuais são insônia, dor de cabeça, fadiga, falta de memória e confusão mental (Achotegui, 2008).

Concebe-se que o processo imigratório é capaz de comprometer o bem-estar do indivíduo, causando uma ruptura biopsicossocial. Não obstante, todo ser humano é capaz de procurar recurso em si próprio e no ambiente que o cerca, para superar os infortúnios, contrapondo a visão de passividade e doença que por vezes é difundida (Angst, 2009). Há diferentes elementos protetivos capazes de fortalecer o ser humano e minimizar os abalos causados, tais como a rede de apoio social, os laços afetivos no sistema familiar e a religiosidade; são aportes emocionais imprescindíveis para a contenção das angústias e manutenção da esperança. 
A chegada em um lugar que se diferencia culturalmente do seu país de origem, sem dinheiro e sem família, onde o futuro é totalmente incerto, exige do sujeito a construção de uma nova vida, e para tanto, ele precisa estar aberto às oportunidades e a redefinições de si mesmo; em contrapartida, sua competência irá depender igualmente da preservação de sua identidade, da manutenção de valores e costumes já definidos.

Sugere-se a elaboração de mais pesquisas e intervenções com imigrantes, com ênfase nos refugiados, para a ampliação de espaços onde tenham voz, visando o acolhimento, a integração à sociedade, a instrumentalização e adequação ao mercado de trabalho, e a redução de danos físicos e psíquicos.

\section{Referências}

Achotegui, J. (2008). Migración y salud mental. El síndrome delinmigrante com estrés crónico y múltiple (síndrome de Ulises). ASMR Revista Internacional On-Line, 7(1), 1-22. Recuperado em 20 março, 2017. ISSN 1579-3516

Alto Comissariado das Nações Unidas para os Refugiados (ACNUR). (2015). Refugiado ou Migrante? O ACNUR incentiva a usar o termo correto. Recuperado em 13 abril, 2017. http://www.acnur.org/portugues/noticias/noticia/refugiado-ou-migrante-oacnur-incentiva-a-usar-o-termo-correto/

Alves, J.F.S; Martins, M.A.C.; Borges, F.T.; Silveira, C. \& Muraro, A.P. (2019). Utilização de serviços de saúde por imigrantes haitianos na grande Cuiabá, Mato Grosso, Brasil. Ciência \& Saúde Coletiva, 24(12), 4677-4686. Recuperado em 07 de dezembro de 2019. http://dx.doi.org/10.1590/1413-812320182412.32242017

Angst, R. (2009). Psicologia e resiliência: uma revisão de literatura. Psicologia Argumento, 27(58), 253-260. Recuperado em 15 abril, 2017, de file://C:/Users/1209-2017/Downloads/20225-34957-1-SM.pdf.

Baeninger, R. \& Peres, R. (2017). Migração de crise: a migração haitiana para o Brasil. Revista Brasileira de Estudos de População, 34(1), 119-143. Recuperado em 10 novembro, 2017. https://dx.doi.org/10.20947/s0102-3098a0017

Bardin. L. (1977). Análise de conteúdo. Lisboa: Edições 70. 
Barros, A. F. O. (2016). Reconstrução em movimento: os impactos psicológicos do terremoto de 2010 em imigrantes haitianos.Dissertação de mestrado, Universidade Federal de Santa Catarina, Florianópolis, SC, Brasil.

Berry, J.W. (1989). Context: Southeast Asians in California.The acculturation process and refugee behavior, 10 (75), 1-12. Recuperado em 05 novembro, 2017. http://www.renincorp.org/context/context-vol-10/cx10-75.pdf

Brandes, L. (2014). Migração Internacional: Implicações psicológicas do retorno do emigrante ao seu lugar de origem. Dissertação de Mestrado, Universidade Vale do Rio, Governador Valadares, MG, Brasil.

Cabistany, L. D. \& Rombaldi, A. J. (2014). Associação entre prática religiosa e estilo de vida saudável em escolares de Pelotas, RS. ABCS Health Sciences - Arquivos Brasileiros de Ciências da Saúde, 39 (2), 64-70. Recuperado em 08 novembro, 2017. http://dx.doi.org/10.7322/abcshs.v39i2.624

Campos, C. J. G. (2004). Método de Análise de Conteúdo: ferramenta para a análise de dados qualitativos no campo da saúde. Revista Brasileira de Enfermagem, 57 (5), 611 614. Recuperado em 06 maio, 2017. https://dx.doi.org/10.1590/S003471672004000500019

Carta, M. G. et al. (2005). Migration and mental health in Europe (the state of the mental health in Europe working group: appendix 1). Clinical practic ean depidemiology in mental health: CP \& EMH, 13 (1), 1-16. Recuperado em 20 maio, 2017. https://dx.doi.org/10.1186/1745-0179-1-13

Cogo, D. (2018) O Haiti é Aqui: mídia, imigração haitiana e racismo no Brasil. Chasqui Revista Latinoamericana de Comunicación, 139, 427-448. Recuperado em 07 de dezembro de 2019. https://revistachasqui.org/index.php/chasqui/article/view/3595+\&cd=1\&hl=pt$\mathrm{BR} \& \mathrm{ct}=\mathrm{clnk} \& \mathrm{gl}=\mathrm{br}$ 
Conselho Nacional De Saúde (Brasil). (2012). Resolução n ${ }^{\circ}$ 466, de 12 de dezembro de 2012. Recuperado em 05 maio, 2017. http://conselho.saude.gov.br/resolucoes/2012/Reso466.pdf

Cotinguiba, G. C. (2014). Imigração Haitiana para o Brasil - A relação entre trabalho e processos migratórios. Dissertação de Mestrado, Universidade Federal de Rondônia Unir, Porto Velho, RO, Brasil.

Dantas, S. (2016). Migração, Prevenção em Saúde Mental e Rede Digital. Remhu: Revista Interdisciplinar da Mobilidade Humana, 24(46), 143-157. Recuperado em 18 maio, 2017. https://dx.doi.org/10.1590/1980-85852503880004610

Dias, S. \& Gonçalves, A. (2007). "Imigração e Saúde”, in Dias, Sónia (org.), Revista Migrações - Número Temático Imigração e Saúde, setembro 2007, n. ${ }^{\circ}$ 1, Lisboa: ACIDI, 15-27. Recuperado em 09 novembro, 2017. http://www.uc.pt/fluc/gigs/GeoHealthS/doc_apoio/migracoes_e_saude.pdf

Dicionário Online de Português (2019). Recuperado em 05 maio, 2017. https://www.dicio.com.br/

Diehl, F. (2016). As ressignificações do conceito de raça e o racismo contra os imigrantes haitianos no brasil. Dissertação de mestrado, Universidade Federal do Rio Grande do Sul, Santa Cruz do Sul, RS, Brasil.

Editora Abril (Janeiro 2017). Revista online Exame:WhatsApp: o idioma dos imigrantes. São Paulo, SP: Autor. Recuperado de https://exame.abril.com.br/tecnologia/whatsappo-idioma-dos-imigrantes/

Elias, N., \&Dunning, E. (1992). A Busca da Excitação. Lisboa: Difel.

Fernandes D., \& Castro, M. C. G. (2014). Estudos sobre a Migração Haitiana ao Brasil e Diálogo Bilateral (Projeto de Pesquisa), Belo Horizonte, BH, Conselho Nacional de 
Imigração (CNIg), Ministério do Trabalho e Emprego do Brasil e a Organização Internacional para a Migração (OIM).

Fernandes, D., \& Faria, A. V. (2017). O visto humanitário como resposta ao pedido de refúgio dos haitianos. Revista Brasileira de Estudos de População, 34(1), 145-161. Recuperado em 05 novembro, 2017. https://dx.doi.org/10.20947/s0102-3098a0012

Ferreira, C. L. (2010). Trabalho, Tempo livre e Lazer: Uma reflexão sobre o uso do tempo da população brasileira. Dissertação de mestrado, Universidade Tecnológica Federal do Paraná, Ponta Grossa, PR, Brasil.

Ferreira, W.F.S; Oliveira, E.C. \& Dutra, D.A. (2018) Imigração Haitiana, Território e Direito à Saúde: uma contribuição da enfermagem. Caderno Saúde e Desenvolvimento, 12(7), 56-67. Recuperado em 07 de dezembro de $2019 . \quad$ https://www.uninter.com/cadernosuninter/index.php/saude-edesenvolvimento/article/download/1030/833.

Franken, I.; Coutinho, M. P. L., \& Ramos, M. N. P. (2012). Representações sociais, saúde mental e imigração internacional. Psicologia: Ciência e Profissão, 32(1), 202-219. Recuperado em 20 março, 2017. https://dx.doi.org/10.1590/S141498932012000100015

Freitas, C. \& Mendes, A. (2013). A resiliência da saúde migrante: itinerários terapêuticos plurais e transnacionais. REMHU: Revista Interdisciplinar da Mobilidade Humana, 21(40), 69-92. Recuperado em 24 março, 2017. https://dx.doi.org/10.1590/S198085852013000100005

Godoy, G. (2011). O caso dos haitianos no Brasil e a via da proteção humanitária complementar. In: Ramos, A.; Rodrigues, G. \& Almeida, G. (Org.). 60 anos de ACNUR: perspectivas de futuro (pp. 15-44). São Paulo: CL-A Cultural.

Guerra, K. \& Ventura, M. (2017). Bioética, imigração e assistência à saúde: tensões e convergências sobre o direito humano à saúde no Brasil na integração regional dos 
países. Cadernos Saúde Coletiva, 25(1), 123-129. Recuperado em 12 outubro de 2017, de https://dx.doi.org/10.1590/1414-462x201700010185

Jardim, D. F. (2016). Imigrantes ou Refugiados? As Tecnologias de Governamentalidade e o Êxodo Palestino rumo ao Brasil no século XX. Horizontes Antropológicos, 22(46), 243-271. Recuperado em 10 março de 2017, de http://dx.doi.org/10.1590/S010471832016000200009

La Rúa, A. F. (2004). Los espacios sociales de la transnacionalidad. Una tipología de la integración relacional de los migrantes. Araucaria Revista Iberoamericana de filosofía, política y humanidades, 6(12), 1-25. Recuperado em 10 novembro de 2017. ISSN digital: 2340-2199.

Lavall, E.; Olschowsky, A. \& Kantorski, L. P. (2009). Avaliação de família: rede de apoio social na atenção em saúde mental. Revista Gaúcha de Enfermagem, 30(2), 198-205. Recuperado em 14 novembro, 2017 https://mc04.manuscriptcentral.com/rgenf-scielo

Lawler, K. A. \& Younger, J.W. (2002).Theobiology: an analysis of spirituality, cardiovascular responses, stress, mood, and physical health. Journal of Religion and Health, 41(4), 347-362. http://www.jstor.org/stable/27511643

Lechner, E. (2007). “Imigração e saúde mental”, in Dias, Sónia (org.), Revista Migrações - Número Temático Imigração e Saúde, setembro, 1, Lisboa: ACIDI, 79-101. Recuperado em 08 novembro de 2017. ISSN: 1646-8104

Lima, A. D. E. O. (2016). O choque cultural na produção do sofrimento psíquico : notas de uma apreciação antropológica do livro A síndrome de Ulisses. Revista Espaço Acadêmico, 16(185), 50-59. Recuperado em 12 março de 2017, de http:/www.periodicos.uem.br/ojs/index.php/EspacoAcademico/article/view/31446/1 $\underline{7598}$ 
Mejía, M. R., Cazarotto, R. T., \& Granada, D. (2014, agosto). Imigração de haitianos para o Brasil: análises de um processo em construção a partir de um estudo de caso. Reunião Brasileira de Antropologia, Natal, RN, Brasil, 29.

Moraes, I., Andrade, C., \& Mattos, B. (2013). A imigração haitiana para o Brasil: causas e desafios. Revista Conjuntura Austral, 4 (20), 95-114. Recuperado em 11 outubro de 2017, de http://dx.doi.org/10.22456/2178-8839.35798

Panzini, R.G. \& Bandeira, D.R. (2007). Coping (enfrentamento) religioso / espiritual. Archives of Clinical Psychiatry, 34 (1), 126-135. Recuperado em 08 novembro de 2017. https://dx.doi.org/10.1590/S0101-60832007000700016

Pereira, A. H. R. (2007). 'O Componente Militar da Missão das Nações Unidas para a Estabilização do Haiti” in Darley, William (Ed.), Military Review (Edição Brasileira), janeiro/fevereiro 2007, n. ${ }^{\circ} 1.2-13$. Recuperado em 11 novembro de 2017. ISSN 10670653

Ramos, N. (2009). Saúde, migração e direitos humanos. Mudanças - Psicologia da Saúde, 17(1), 1-11. Recuperado em 20 março de 2017. file://C:/Users/12-092017/Downloads/1924-4293-2-PB\%20(1).pdf

Rodrigues, V. M. (2013). Migrantes Haitianos no Brasil: Mitos e contradições. Santiago do Chile, ALAS. Recuperado em 10 novembro de 2017. http://actacientifica.servicioit.cl/biblioteca/gt/GT9/GT9_MozineRodriguezV.pdf

Semedo, M. M. (2016). Depressão, Estratégias de Coping e Resiliência: Estudo Transcultural com Imigrantes Cabo-Verdianos e Brasileiros. Dissertação de Mestrado, Universidade Lusófona de Humanidades e Tecnologias, Lisboa, Portugal.

Trad, L. A. B. (2003). Processo migratório e saúde mental: rupturas e continuidade na vida cotidiana. Physis: Revista de Saúde Coletiva, 13(1), 139-156. Recuperado em 10 março de 2017, de https://dx.doi.org/10.1590/S0103-73312003000100007 
Von Mühlen, B.; Dewes, D. \& Leite, J. (2010). Stress e processo de adaptação em pessoas que mudam de país : uma revisão de literatura. Revista Ciência em Movimento, 12(24), 59-68. Recuperado em 10 março de 2017, de https://www.metodista.br/revistas/revistas-ipa/index.php/CMBS/article/view/61/36

Zeni, K. \& Filippim, E. S. (2014). Migração haitiana para o Brasil: acolhimento e políticas públicas. Revista Pretexto, 15 (2), 11-27. Recuperado em 10 novembro de 2017. http://dx.doi.org/10.21714/pretexto.v15i2.1534 